\title{
Saúde e espaço urbano: entrelaces de saberes em contexto de pós-graduação
}

\author{
Health and urban space: intertwining knowledge \\ coming from different areas in a postgraduate context
}

Doralice Barros Pereira [I]

Waleska Teixeira Caiaffa [II]

Veneza Berenice de Oliveira [III]

\begin{abstract}
Resumo
Buscamos uma mais rica interlocução entre urbanização/metropolização e os processos de saúde, doença e educação profícua às pesquisas, ao ensino e às políticas públicas. A crescente urbanização e concentração nas metrópoles insta-nos a apresentar as reflexões e experiências da/ na disciplina Saúde e Espaço Urbano (SEU). 0 viver na cidade pensado sob a forma de estratégias que respondam às implicações em saúde e problemas sociais afeitos às iniquidades em saúde, como violência, trânsito, doenças (re)emergentes, transmissíveis ou não, estimula uma abordagem inter/transdisciplinar. Nessa disciplina, primamos por uma formação e capacitação discente holística, voltada a uma vida urbana saudável e com maior conhecimento, resultante do entrelace de saberes de três Pós-Graduações da UFMG, Geografia, Saúde Pública e Arquitetura, desde 2015.
\end{abstract}

Palavras-chave: saúde urbana; formação e capacitação em saúde; determinantes urbanos de saúde; tecnologia da informação em saúde urbana; desigualdades e iniquidades sociais urbanas.

\begin{abstract}
We intend to build a richer interlocution between urbanization/metropolization and the processes of health, disease and education, beneficial to research, teaching and public policies. The growing urbanization and concentration in metropolises urge us to present reflections and experiences of/ in the discipline Health and Urban Space (SEU, in Portuguese). Living in the city, conceived in the form of strategies that respond to health implications and social problems related to health inequities such as violence, traffic and (re)emergent diseases, transmissible or not, stimulates an inter/ transdisciplinary approach. In this discipline, we have been providing a holistic education and qualification for students since 2015, focusing on a healthy and more knowledgeable urban life, resulting from the intertwining of knowledge deriving from three Postgraduate Programs of the Federal University of Minas Gerais (UFMG): Geography, Public Health and Architecture.
\end{abstract}

Keywords: urban health; health education and qualification; urban determinants of health; information technology in urban health; social and urban inequalities and inequities. 
Na medida em que os homens, dentro de sua sociedade, vão respondendo aos desafios do mundo, vão temporalizando os espaços geográficos e vão fazendo história de sua própria atividade criadora. (Freire, 1982, p. 23)

\section{Introdução}

A intensa urbanização, em termos mundiais e nacionais, está intrinsicamente relacionada à transição epidemiológica e demográfica, aumentando significativamente pressões distintas sobre os ambientes (espaços disponíveis e adequados para abrigar as pessoas), sobre as próprias populações em suas necessidades (saúde, educação, emprego, habitação, alimentação, lazer e cultura) e sobre grupos populacionais específicos, como os idosos e as pessoas com deficiência (Caiaffa e Friche, 2012; Caiaffa et al., 2010; Caiaffa et al., 2008). Essas transições incidem também em diversas mudanças de comportamento, advindas, de um lado, na/da precariedade do trabalho, tristeza, dor, sofrimento, saúde e doença - ou seja, o viver nas cidades pode também ampliar o mal-estar -, e, de outro lado, elas podem fomentar alegrias, satisfação e plenitude, qualificando mais e melhor nossas vidas.

Entendemos, como urbano, o espaço político e construído culturalmente, palco de diferentes formas da ação territorial (Souza, 2000), no qual atuações de origens diversas ocorrem, tais como as do Estado, detentor do poder político, e as de grupos que compõem o ambiente urbano (a exemplo do mercado imobiliário, do transporte, das forças populares, etc.). A urbe abrange uma região em que são traduzidos o dinamismo do mundo contemporâneo, com múltiplas funções e serviços. Concentra a maior parte da riqueza nacional e também os expressivos focos de pobreza e de exclusão social. Portanto, nela se potencializam novas formas de produção e de modos de vida.

Entendemos, como saúde, a compreensão do homem em sua integralidade e multidimensionalidade, conforme as dimensões de Röhr (2011, p. 53): física, sensorial, emocional, mental e espiritual, bem como conforme inúmeras outras dimensões temático-transversais e em consonância com a Organização Mundial da Saúde.

O diagnóstico a que chegamos é que são enormes os desafios para a produção do conhecimento científico local considerando o contexto político nacional e internacional. $E$, em especial, quando se reduzem cada vez mais os investimentos nas ciências, acompanhado de ataque constante ao conhecimento científico, particularmente às Ciências Humanas, Sociais e Básicas, revelando um projeto tecnocrático e utilitarista para o campo das Ciências e da Tecnologia. Assim, propomos centrar esforços nas tentativas de construção de um saber urbano mais holístico, ligado aos setores mais caros à vida, quais sejam: saúde, educação, cidade/ambiente e todos os demais elementos que os compõem e neles se imbricam.

Este texto, dividido em cinco partes, expõe justificativas e desdobramentos da criação da disciplina de Pós-Graduação Saúde e Espaço Urbano (SEU). De início, trataremos 
do pensar a inter/transdisciplinaridade dos temas/práticas apoiados em nossos saberes e práticas, e esclarecemos que a disciplina não é fruto de parceria direta da universidade com órgãos de gestão da Região Metropolitana de Belo Horizonte; em seguida, discutiremos conceitos ligados às discussões empreendidas no âmbito da disciplina, como o urbano, a saúde e seus elos. Na terceira parte, entrelaçaremos as reflexões precedentes às atividades que compõem a disciplina, para que se possa apontar um modo de apreender mais e melhor a inter e transdisciplinaridade que saúde e espaço urbano exigem. Registraremos algumas manifestações dos discentes e, de forma breve, finalizaremos pensando a intersecção saúde e espaço urbano/metrópoles em face da Covid-19.

\section{Pensando a inter e transdisciplinaridade dos temas/práticas}

Desde o final do século XIX, a ciência tem passado por divisões e subdivisões, abrindo novos campos e subcampos do saber, o que resulta na fragmentação e no parcelamento de diversas temáticas. Como alcançar maior excelência, que seja profícua ao debate, à educação ${ }^{1}$ / formação e à capacitação dos profissionais, numa abordagem inter e transdisciplinar, pontuando saúde e espaço urbano?

Hodiernamente pensar e trabalhar a educação, a ciência e a humanidade requerem o estar atento à conjuntura na qual o Estado ${ }^{2}$ tem, ele também, negado direitos humanos, uma das maiores tensões políticas ao longo da história. Consideramos oportuno enfrentar a relação/ conexão de saberes a partir de uma proposta pedagógica inclusiva e de qualidade social, na qual o compromisso com o ser humano nos conduza a ter em conta a saúde (implicando o sistema e as políticas) voltada para se ter uma vida urbana saudável e com dignidade.

Para tal tarefa, demanda-se do educador, junto ao educando, ofertar maior relevância ao tecido social e à tradição da comunidade na qual ele trabalha, para que se aproxime mais dos conteúdos da realidade vivida. Esse movimento intenta compor um diálogo aberto com o(a) aluno(a), para justificar e evidenciar cada vez mais a "razão de ser" do conhecimento, colaborando para aguçar o interesse e a curiosidade social e científica.

$\mathrm{Na}$ interlocução saúde e espaço urbano, o impasse é manter a saúde. Ela pode ser mais inacessível para uns grupos sociais do que para outros, em especial em face das vulnerabilidades - trabalhadores informais, indígenas, imigrantes, refugiados, sem abrigo, moradores das periferias pobres e favelas, ${ }^{3}$ pessoas com necessidades especiais, sexo (pois o gênero pode remeter a uma categoria asséptica e ser analisado isoladamente), classes, idade, xenofobia e racismo, violências e estigmatizações, ${ }^{4}$ o discurso de ódio - (Cordeiro, 2020; Santos, 2020; Ralón et al., 2012; Friche et al., 2015a e b). A ocorrência de evento epidemiológico (a exemplo da dimensão da Covid-19), desastres ambientais e/ou crises financeiras tendem a agravar sobremaneira a situação anterior. É imperioso pesar tais vulnerabilidades, pois economia e saúde estão cada vez mais se fragmentando, degradando e precarizando as políticas sociais, a privatização dos serviços, as reduções de financiamentos, ou seja, levando a uma imposição de uma austeridade significativa. Questionamos, assim, a capacidade efetiva do Estado para responder eficazmente à crise 
que abate os cidadãos, por ser preciso sair do sombreamento do darwinismo social e vencer a sobrevivência dos corpos socialmente mais valorizados (ou seja, aqueles com saúde, vigor e disposição), mais aptos e mais necessários para a economia. Vale lembrar o importante papel e atuação do Sistema Único de Saúde (SUS) no Brasil, que, mesmo em processo de franca precarização nos últimos anos, profundamente agravado pela Ementa Constitucional n. 95 (EC95) (Brasil, 2016), tem exercido papel fundamental em todos os níveis de atenção, garantindo assistência integral e de qualidade aos usuários (Costa et al., 2020).

Todas essas dificuldades merecem ser combatidas e, para tanto, o conhecimento é uma via crucial. Educadores e educandos, estimulados mutuamente, além de obterem conteúdos programáticos que despertem a curiosidade e consequentemente a busca por conhecimento, também evocam a imaginação, a intuição, a capacidade de comparar, de transformar e transcender. Esse movimento exige a capacitação tanto dos discentes quanto de todo cidadão, para a comunicação e o diálogo com entidades responsáveis pelos setores de saúde, como também a formação de novas parcerias, que, articuladas, facultem novas formas de participação política junto às agências governamentais, aos fóruns de debates e às reuniões com representantes institucionais.

0 trabalho pedagógico e de sensibilização, diante de tantas fragilidades e desafios, esbarra no aumento de demandas por atendimento e tratamento de saúde dos cidadãos e exige um amálgama mais pulsante entre saúde e políticas urbanas. É salutar, então, abrir as convergências de conhecimentos e saberes, a sinergia do planejamento de políticas urbanas com as universidades. Quanto à elaboração de um planejamento metropolitano, nota-se a necessidade de uma entidade atuante, responsável por tal mister em Belo Horizonte, pois a autarquia estadual de planejamento urbano - Superintendência de Desenvolvimento da Região Metropolitana de Belo Horizonte (Plambel) - foi extinta em 1996 e, apenas uma década depois, foi criada a Agência de Desenvolvimento da Região Metropolitana de Belo Horizonte, cuja atuação em termos de articulação interinstitucional ainda é frágil.

Os esforços conjuntos entre universidades e entidades metropolitanas para a produção de dados, estudos, conhecimentos e propostas mais afeitos a um planejamento regional metropolitano interligado e permanente certamente têm o potencial de trazer maior acuidade para identificar as tendências de crescimento e necessidades que estão na ordem do dia. Os primeiros esforços articularam práticas de extensão com ensino e pesquisa, realizados de 2009 a 2011, na elaboração do Plano Diretor de Desenvolvimento Integrado para a RMBH (PDDI-RMBH) e no Macrozoneamento (uma das políticas do PDDI) de 2013 a 2015 (Costa e Monte-Mór, 2018). Alguns municípios já revisaram seus planos diretores com base no PDDI e no Macrozoneamento e/ou incorporaram propostas do PDDI às políticas locais. A disciplina SEU beneficia-se de análises e materiais produzidos dessa iniciativa, sem ter parceria com tais agências ou secretarias.

Por meio da educação, tem-se uma das formas de intervenção no mundo, que não é neutra nem indiferente, mas elaborada e, certamente, eliminadora de lacunas. Assim, nessa condição, desde 2015, a disciplina Saúde e Espaço Urbano vendo sendo construída entre três cursos de Pós-Graduação - Saúde Pública, Arquitetura e Urbanismo e Geografia -, todos 
da Universidade Federal de Minas Gerais. Essa disciplina explora o viver na cidade, por representar a mudança demográfica mais importante das últimas décadas e para buscar estreitar laços e oportunidades nos territórios urbanos: uma abordagem inovadora para a capacitação em saúde e ciências afins.

Enovelar a pesquisa, as práticas e o ensino corresponde a sair da verticalidade que as especializações disciplinares ainda retêm. A complexidade dessas questões interpela o grupo de professores e pesquisadores oriundos de diferentes campos da saúde pública e da epidemiologia, do planejamento urbano, da geografia, da demografia, da arquitetura e da tecnologia da informação, que se esforçaram e se esforçam em empreender a disciplina SEU, não para esgotar os temas e, sim, para colocá-los na ordem do dia, mantê-los reluzentes e na temática cotidiana.

A disciplina SEU é destinada a discentes de mestrado e doutorado e se propõe, a partir de uma abordagem inter e transdisciplinar, a conjugar o crescimento urbano e suas características múltiplas no que se refere à saúde e à demanda por serviços e por uma melhor qualidade e estilo de vida. Somam-se aí ainda questões ligadas às desigualdades injustas ou iniquidades sociais (Cordeiro, 2020), que estão a exigir dos profissionais, e mesmo do cidadão comum, uma visão e formação sistêmicas plurais, cada vez mais profusas. Logo, é urgente e oportuna uma avaliação do contexto ambiental e urbano em termos de saúde e produção do espaço urbano, focando, de forma sistêmica, nas relações e nos processos que decorrem do poder desigual de acesso e atendimento aos serviços de saúde, em uma cidade formal e informal. Vale ainda identificar relações sociais solidárias, coletivas e horizontais, que melhor facultem uma tessitura social de convivência saudável, para torná-la mais autônoma e independente.

Todo esse panorama serve para justificar a criação da disciplina, que, além da formação, pode colaborar com a elaboração/discussão e decisão de políticas públicas em diferentes patamares e escalas. Enquanto seres sociais e históricos, mesmo inseridos em uma estrutura social desigual, merecemos ser mais bem capacitados para identificar, entender e quiçá mediar as ideologias, as necessidades e aspirações dos cidadãos e, assim, trazer à tona uma compreensão de saúde emparelhada com as determinações sociais, a fim de as superar e evitar a destruição da vida.

\section{O urbano, a saúde e seus elos: acepções dos principais conceitos na perspectiva interdisciplinar}

A literatura afeita à temática é abundante e optamos por ser mais genéricos e indicar o crescimento do tema. A disciplina alicerça-se nas discussões dessa literatura, abordando os elos e interações entre o urbano e a saúde, sobretudo na perspectiva dos determinantes sociais e ambientais, trazendo, para o contemporâneo, conceitos e discussões da ecologia urbana, dos sistemas urbanos, da saúde global e planetária.

Uma consulta rápida no PubMed, ${ }^{5}$ um dos mais completos bancos de dados de pesquisa bibliográfica, foi possível verificar essa tendência. Utilizando o unitermo "urban health", observou-se um aumento significativo de publicações nas últimas décadas. De 2.264 
referências no ano 2000, elas saltaram para 11.231 no ano de 2020. A mesma tendência foi verificada para os livros, ou seja, de um livro no ano 2000 passou-se para 15 livros, em 2020.

Viver na cidade representa a mudança demográfica mais importante ocorrida nas últimas décadas. No Brasil, o percentual de pessoas vivendo em cidades gira em torno de $84,4 \%$ da população, segundo o IBGE (2017), em conformidade com a nova proposta para uniformizar a classificação de áreas urbanas e rurais. Pelo critério anterior, em 2010, cerca de $76 \%$ da população residia em zonas urbanas (Abep, 2017). Certo é que ambos os dados exigem reflexões, políticas e ações para termos pessoas e cidades mais saudáveis e não uma análise precipitada e aparente, sem buscar os nexos e consequências de suas evidências.

A inovação trazida pela disciplina consiste em fazer uma análise crítica voltada à promoção da saúde nos vários territórios da cidade. A articulação institucional com outras entidades públicas e privadas, bem como com representantes da sociedade civil em geral, visa agregar maior visibilidade para grupos, territórios e ações. É também um "sair da academia", para estabelecer interlocução com contextos sociais municipais e metropolitanos díspares e eliminar barreiras e limites colocados pelas abordagens setoriais tradicionais e epistemológicas. Ganham relevo, na disciplina, os eixos temáticos voltados à urbanidade, acessibilidade, sustentabilidade e segurança. Por conseguinte, perguntamo-nos "por que é importante demarcar o espaço urbano?". Além da crescente elevação da taxa de urbanização, outros elementos merecem atenção por incidirem no cotidiano das pessoas: uma vivência em escala local acoplada à conformação de outros polos dialéticos de conectividade: local versus global; política: municipal versus internacional; e na vida e tradição cotidiana: natural versus social.

Somos partidários, quanto à apreciação do espaço, da colocação de Lefebvre (1976, p. 31):

\begin{abstract}
Não é um objeto científico afastado da ideologia e da política; sempre foi político e estratégico. Se o espaço tem uma aparência de neutralidade e indiferença em relação a seus conteúdos e, desse modo, parece ser "puramente" formal, a epítome da abstração racional é precisamente por ter sido ocupado e usado, e por já ter sido o foco de processos passados cujos vestígios nem sempre são evidentes na paisagem. $O$ espaço foi formado e moldado a partir de elementos históricos e naturais, mas esse foi um processo político. O espaço é político e ideológico. É um produto literalmente repleto de ideologias.
\end{abstract}

A dialética dos centros e das centralidades e a constituição dos "centros de decisão, de riqueza, de poder, de informação, de conhecimento" provocam o deslocamento da centralidade, do encontro e da reunião. A qualidade constitutiva do espaço urbano é essencial às práticas urbanas.

Estudar o espaço urbano merece ir além do localizar, no espaço preexistente, uma necessidade ou uma função, de espacializar uma atividade social ligada a uma prática no seu conjunto, produzindo um espaço apropriado. Ao atentar para a apropriação, há possibilidades de melhor determinar a junção, a articulação desses dois "níveis", o micro e o macro, a ordem próxima e a ordem distante, a vizinhança e a comunicação.

Não é demais frisar que a cidade, em sua história, passou "da produção das coisas no espaço à produção do espaço planetário. Esta, 
envolvendo, supondo aquela. Passa-se da consideração clássica dos lugares de implantação industrial ao espaço inteiro" (Lefebvre, [1972], 2010, p. 4).

A realidade urbana implica um centro, uma reunião de tudo o que pode nascer no espaço e nele ser produzido; um encontro atual ou possível de todos os "objetos" e "sujeitos". Tais centralidades podem, inclusive, ser redefinidas, destruídas ou criadas na esteira de acumulações primitivas do espaço, mediante estratégias de valorização que canalizam, a seu favor, espacialidades até então "desinteressantes" ao capital. É assim que, no curso do processo acelerado de urbanização, as pessoas, os trabalhadores dispersados, distanciados dos centros urbanos, geraram a extensão das cidades, e, por conseguinte, deu-se a segregação econômica, social, cultural (Caiaffa e Friche, 2012).

A noção de periferia resulta de uma "constatação lógica", endossando a sua separação permanente daquilo que seriam as centralidades (de poder e de riqueza). Não obstante, a periferia é metrópole, vivendo suas contradições específicas e ainda as mais gerais advindas do curso da reprodução das relações sociais da e na metrópole. Nesse movimento, a periferia também é centralidade: as contradições materializam-se nos embates, podendo fazer dessas espacialidades o lugar onde a política irrompe, ganha e dá sentido às práticas de seus moradores: as classes populares (Andrade, 2008).

0 urbano nasce com a explosão-implosão da cidade (Lefebvre, 2008). Seu estudo demandaria uma colaboração inter e transdisciplinar? 0 urbano distingue-se da cidade precisamente porque ele aparece e se manifesta no curso da explosão da cidade (ibid.). 0 urbano permite reconsiderar e compreender certos aspectos da cidade que ficaram alheios durante muito tempo: a centralidade, o espaço como lugar de encontro, a monumentalidade, etc. (Lefebvre, 2000). 0 urbano trata, antes, de uma forma: a do encontro e da reunião de todos os elementos da vida social, desde os frutos da terra (trivialmente, os produtos agrícolas) até os símbolos e as obras ditas culturais (Lefebvre, 1969). No próprio seio do processo negativo da dispersão, da segregação, o urbano se manifesta como exigência de encontro, de reunião, de informação (Lefebvre, 2000).

A modernidade, como processo unitário, atribuía sentido aos conteúdos da vida de bairro. Mesclava o arcaico com o moderno até no limite, redefinindo o todo e as partes. 0 bairro é uma inscrição espacial primordial, fundada em certo localismo, que lhe confere identidade e distinção. O bairro remete ao cotidiano e é no e pelo cotidiano que as relações sociais fundamentais - de produção, de propriedade, de consumo e de trabalho -realizam-se e ganham vigor, tendendo a se naturalizarem como o ordinário da vida (trabalho, vida privada, lazer) (Lefebvre, [1968] 1991). O cotidiano

\section{é aquilo que nos é dado cada dia (ou que nos cabe em partilha), nos pressio- na dia após dia, nos oprime, pois existe uma opressão do presente. Todo dia, pela manhã, aquilo que assumimos, ao despertar, é o peso da vida, a dificuldade de viver, ou de viver nesta ou noutra con- dição, com esta fadiga, com este desejo. (De Certeau, Giard e Mayol, 1998, p. 31)}

Com o afastamento do homem de seu ser natural, o cotidiano (rico de subjetividades) cria um vazio que ocorre com a organização e a burocratização da vida. Ele só poderá "preencher" tal vazio fornecendo 
"escapatórias" às suas pressões e repressões. 0 cotidiano é construído dia a dia, com o fazer singular do indivíduo em vários contextos sociais dos quais participa. A vida cotidiana constitui-se, então, "no conjunto de atividades que caracterizam a reprodução dos homens particulares, os quais, por sua vez, criam a possibilidade de reprodução social. A vida cotidiana é a vida de todo homem" (Heller, 1992, p. 17).

A problemática do espaço vivido é um aspecto importante e talvez essencial no processo de conhecimento da realidade urbana; sendo próprio da teoria do urbano e da sua ciência, representa uma problemática mais vasta: a da conexão com a sociedade global. Assim, os territórios urbanos modernos geram assentamentos urbanos irregulares, reveladores de intensas segregações socioespaciais, cuja produção detém uma imensa desigualdade intraurbana e injusta distribuição dos agravos em saúde das populações que vivem nessas áreas vulneráveis.

Consoante com os Objetivos de Desenvolvimento Sustentável (ODS n. 11/2016), que pontua a necessidade urgente de "Tornar as cidades inclusivas, seguras, resistentes e sustentáveis", a amplitude do enunciado remete à necessidade de se atingir uma dimensão de saúde mais ampla, de acordo com o ODS n. 3, que visa assegurar uma vida saudável e promover o bem-estar dos indivíduos. Assim considerando, o caráter nitidamente intersetorial facilita o compartilhar de compromissos com os outros ODS em prol da saúde na Agenda pós-2015, por meio de novos modelos de governança, que incluem objetivos compartilhados, planejamento conjunto e ações intersetoriais (Buss et al., 2014; Caiaffa et al., 2008 e 2010).

Em espaços degradados/marginalizados, há, não só um aumento de doenças, mas uma diversidade delas, pois, em geral, a segregação territorial de vilas e favelas nas grandes cidades é acompanhada da falta de infraestrutura sanitária. Além de serem mais prejudiciais à saúde, esses espaços também são ambientes férteis para a maior incidência e presença de violências (Dias et al., 2019; Dayrell e Caiaffa, 2012). Assim, a identificação das combinações entre as condições e situações dos ambientes com a propensão de doenças e/ou incidências de certos fatores patógenos pode melhor nos auxiliar a reduzir ou eliminar as condições de adoecimento das pessoas.

Pontuamos aqui um movimento que retroalimenta o ambiente-saúde-ambiente. Essa interação exige reflexões referentes à construção de um arcabouço conceitual do campo da saúde urbana, que vá se refinando à medida que um ramo da saúde pública considere que os territórios onde se vive interagem e influenciam com/o modo de viver das pessoas e podem estar também sob a incidência de determinantes, como os da violência urbana, por exemplo. Essa via pode contribuir para que projetos estruturantes de urbanização de vilas e favelas (p. ex. Projeto Vila Viva - PAC da Prefeitura de Belo Horizonte), ${ }^{6}$ voltados à inclusão na cidade formal, melhorem a qualidade de vida das pessoas que ali residem. 


\section{Os conteúdos mesclados com as reflexões em direção à construção de práticas de inter e transdisciplinaridade}

Ninguém educa ninguém, como tampouco ninguém se educa a si mesmo: os homens se educam em comunhão, mediatizados pelo mundo. (Freire, 1987, p. 79)

Diante do desafio de abarcar ao máximo a totalidade do que se coloca na metrópole e em sua periferia, a disciplina SEU orienta sua atenção para o interagir, emergir e cruzar de temas que perpassam a saúde urbana e o urbanismo, como: as discussões conceituais acima, a apresentação de métricas e estrutura conceitual tanto afeitas à saúde urbana quanto ao espaço urbano; debate as potenciais interseções e peculiaridades entre urbanismo e saúde, bem como ecologia urbana (ambientes e sistemas naturais presentes no urbano) e quanto a presença da agricultura, em meio urbano, desdobra-se nas questões da alimentação e nutrição. Aqui, ganha fôlego a discussão sobre alimentação saudável e o uso de plantas medicinais a partir de uma aula prática de preparação de alimentos.

Para captar com maior acuidade as diferenças intraurbanas em termos de saúde e urbanização, por meio do uso e aplicação da tecnologia da informação, múltiplos elementos e parâmetros são identificados e mensurados de modo a favorecer o melhor acompanhamento da construção e performance dos determinantes ambientais e de saúde urbana, uma vez que estes interferem, por exemplo, no acesso e na mobilidade para alcance dos equipamentos urbanos e de serviços de saúde (como academias ao ar livre, centros comunitários, centros de saúde, áreas verdes como praças) (Souza et al., 2016).

Todo esse conjunto de fatores dispõe de implicações nas relações entre espaços de vida e processos de saúde/doenças, pois os determinantes sociais conectam a saúde. Assim, são oportunas as abordagens sistêmicas e de múltiplos níveis que pensem a saúde urbana e as políticas urbano-ambientais; intervenções urbanas, vulnerabilidade e saúde; mobilidade urbana e saúde; determinantes ambientais (espaços livres/verdes) e implicações sobre a saúde. A disciplina é ofertada no segundo semestre do ano e tem seus conteúdos ministrados, em geral, em 15 encontros, em exposições e práticas, além de leituras prévias enviadas aos discentes para um melhor aproveitamento do material exposto/debatido. Há também o uso de filmes curtos, música, imagens e relatos de vivências dos discentes e docentes. Para prestigiar e fazer conhecer outros espaços da universidade, as aulas são itinerantes e distribuídas entre as três unidades que as ofertam: Faculdade de Medicina, Escola de Arquitetura e Instituto de Geociências.

Em termos de conteúdo, as aulas versam sobre: • Saúde urbana: modelos conceituais e métricas; • Saúde e urbanismo: conceitos, fundamentos, interseções e peculiaridades; - Ecologia urbana, agricultura urbana e ambiente alimentar; • Tecnologia da informação no espaço urbano; • Saúde urbana e seus determinantes: ambiente social, natural e construído; • Relação entre vida urbana e processo saúde/doença; • Determinantes sociais da saúde; • Serviços de saúde no ambiente urbano - fundamentos do SUS e sobrecarga do sistema; • Abordagem multinível e dos 
sistemas dinâmicos; • Abordagens dos estudos chamados de experimentos naturais ou quase-experimentais; • Vivências urbanas.

0 grupo de professores/pesquisadores dos campos de conhecimento da epidemiologia e saúde urbana, planejamento urbano, geografia urbana, arquitetura e tecnologia da informação (TI) decidiu trabalhar de forma interdisciplinar para: 1) experimentarem novas colaborações pedagógicas e de pesquisas no campo multidisciplinar, compartilhando experiências de como o planejamento urbano pode promover o bem-estar, reduzir a pobreza e a violência (assim como prevenir e combater a violência policial), além de tratar de questões da equidade em saúde (Caiaffa e Friche, 2012); 2) disponibilizarem uma nova disciplina (optativa, eletiva) para alunos inseridos em pós-graduação (mestrado e doutorado) e para a comunidade (disciplina isolada); beneficiando-se os discentes também das afiliações de que os três cursos de Pós-Graduação e seus membros participam, a exemplo do Observatório de Saúde Urbana da Faculdade de Medicina da UFMG (OSUBH/UFMG), que tem como parceiros em suas pesquisas, entre outros, a Secretaria Municipal de Saúde de Belo Horizonte.

Algumas atividades das experiências interdisciplinares/transdisciplinares vivenciadas na disciplina SEU consideraram em sua trajetória munir os discentes de elementos que thes permitissem elaborar uma discussão nos níveis de observação, identificação e descrição das questões, a partir de arcabouços teórico-conceituais, metodológicos e epistemológicos. Para melhor expressar as dinâmicas efetuadas na disciplina, apresentaremos brevemente, a seguir, algumas atividades/vivências feitas a partir de 2015. As atividades são previamente discutidas entre os docentes e escolhidas de acordo com a temática urbana vigente, levando-se em consideração o perfil dos discentes, que são meticulosamente organizados em grupos multidisciplinares.

Em 2015, o estudo de campo ocorreu a partir de uma interlocução com os representantes do Projeto BH-Viva. Fizemos uma visita ao Aglomerado da Serra (nota de rodapé 6), com o objetivo inicial de conhecer e se familiarizar com um espaço informal, observando-se sua estrutura física (água, saneamento, habitação, posse da terra, eletricidade), bem como as condições sociais (exclusão social ou discriminação, pobreza, desigualdade de renda, sexo, entre outros), além de verificar a disponibilidade de ações participativas das diversas esferas de governo (educação, oportunidades de emprego, entre outros). Posteriormente, em outro ponto do Aglomerado, foi possível identificar as alterações promovidas pelo programa, bem como discutir aspectos da história de ocupação e vivência no Aglomerado, explicitando as diferenças intraurbanas. Foram visitadas, também, casas dos moradores relocados pelo Projeto Vila Viva.

Em 2016, foi empreendido um estudo no campus da Pampulha (Figura 1), região Norte de Belo Horizonte, com visitação à Estação Ecológica do Campus da UFMG (114 ha). A discussão esteve afeita aos espaços verdes preservados ecologicamente, em meio aos espaços densamente construídos e que tornam complexas as questões de sustentabilidade e manutenção da biodiversidade urbana (Alho, 2012).

Lançando mão da tecnologia de informação e com uso de aplicativos (apps), fomos pioneiros, em 2016, com a experiência do "aprender fazendo". Com o celular enquanto ferramenta, usamos mapas disponíveis na Web e plataformas colaborativas (Figura 2). 
Figura 1 - Estação Ecológica da Universidade Federal de Minas Gerais, Belo Horizonte, MG

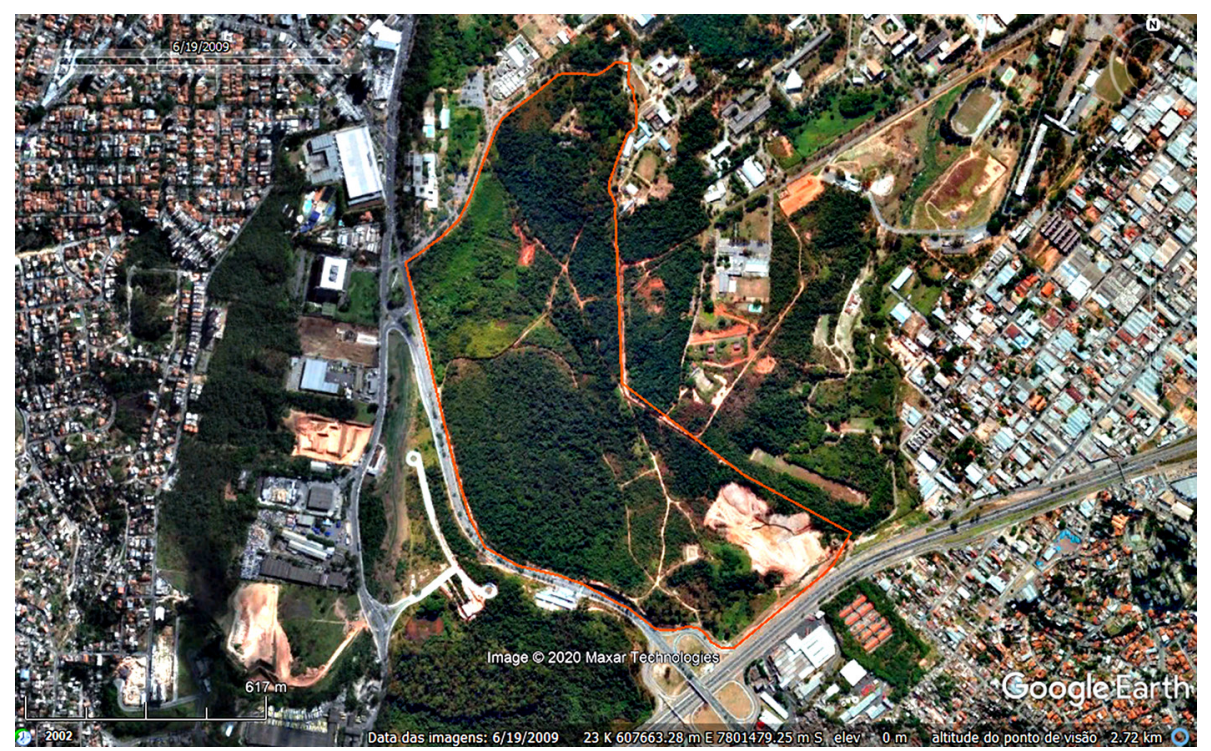

Imagem aérea, altitude do ponto de visão = 3,94 km. Limite da E.E. - UFMG. Perímetro 4,36 km e área 0,79 km². Fonte: Google Earth.

Figura 2 - Uso significativo de dispositivos: fortalecimento dos componentes do lugar

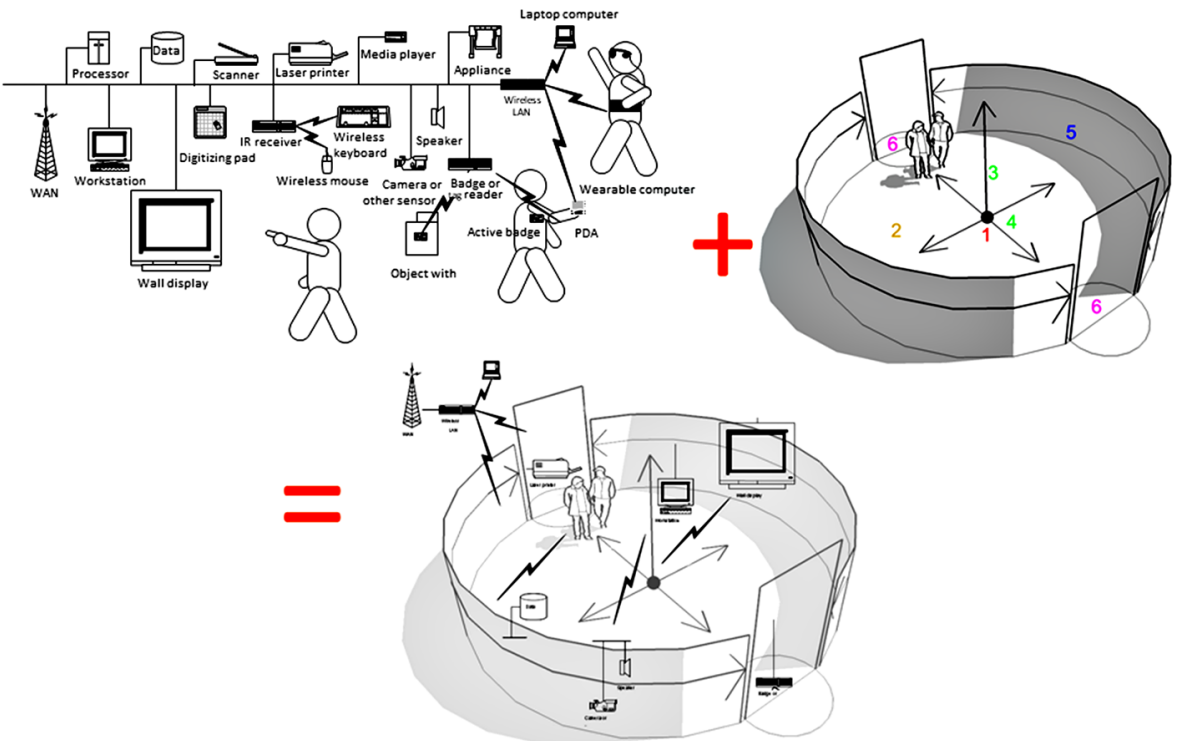

1) Centralidade; 2) Área interna; 3) Direções verticais; 4) Direções horizontais; 5) Fechamentos (enclosure);

6) Transições

Fonte: Arquivo da Disciplina, 2015 a 2020. Imagens montadas para a disciplina. 
O objetivo era perceber, entre outros elementos arquitetônicos, a presença e disposição de equipamentos, a territorialidade, a privacidade, a identidade dos ambientes quanto aos aspectos geográficos e àqueles afeitos à percepção de segurança, atendimento médico acessível e/ou facilidade para mobilidade.

O uso de programas e aplicativos da Tecnologia da Informação para definição dos pontos de análise espacial foi adotado algumas vezes. Por exemplo, a plataforma Ushahidi foi utilizada para a identificação dos serviços de saúde disponíveis e sua relação espacial. Essa plataforma foi confeccionada para mapear a violência no Quênia, desde 2007, e, atualmente,
Grupos da sociedade civil e indivíduos ao redor do mundo têm usado Ushahidi para mapear desastres naturais, epidemias e distúrbios civis e para promover uma ampla variedade de causas sociais, políticas e ambientais. (ShareAmerica, 2015)

A plataforma e seus recursos de captação de dados foram aplicados para verificar as condições de acessibilidade, mobilidade, localização e ambientais no exercício feito no campus da Pampulha/UFMG. As Figuras 3 e 4 mostram a aplicação da plataforma a seguir e os pontos visitados nos quais foram preenchidos questionários para detectar o estado das variáveis mencionadas, aliando percepção in loco, dados, mapeamento e tecnologia.

Figura 3 - Interface de ferramentas na área de trabalho para avaliação ambiental

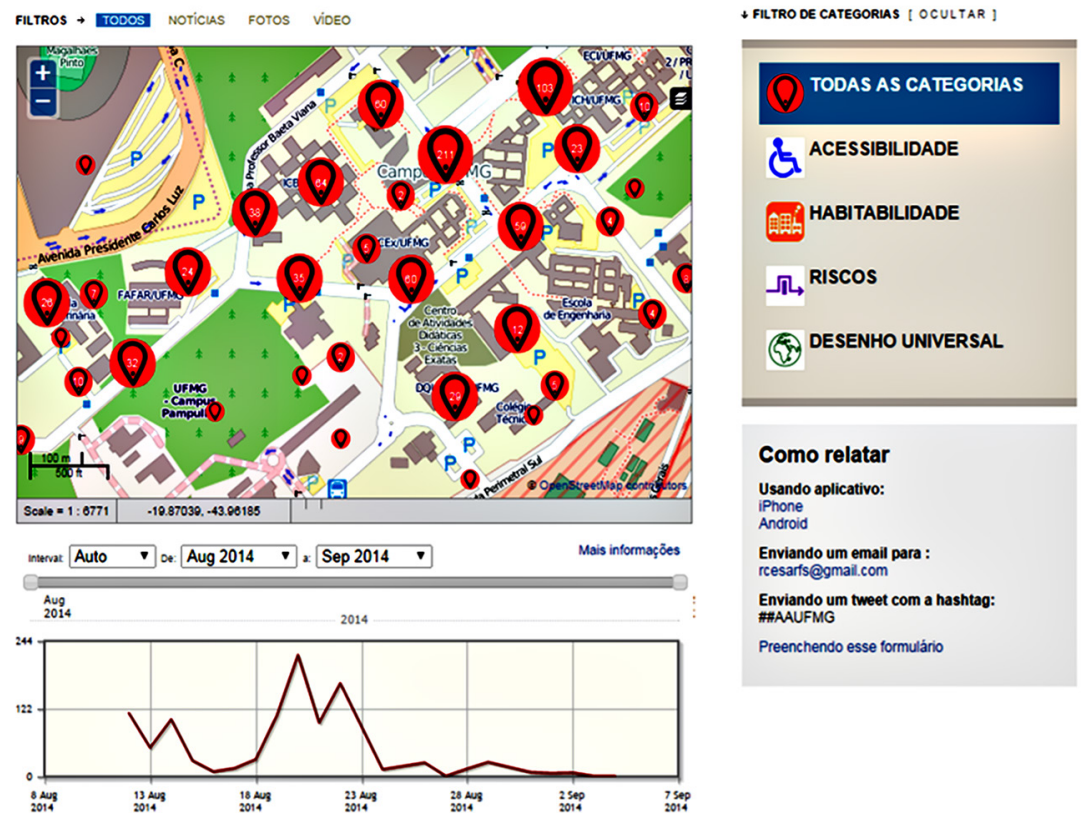

Fonte: Arquivo da Disciplina, 2015 a 2020. Imagens montadas para a disciplina. 
Figura 4 - Uso da plataforma Ushahidi como ferramenta para Avaliação Ambiental do campus UFMG Pampulha, em conjunto com um questionário de critérios de observação
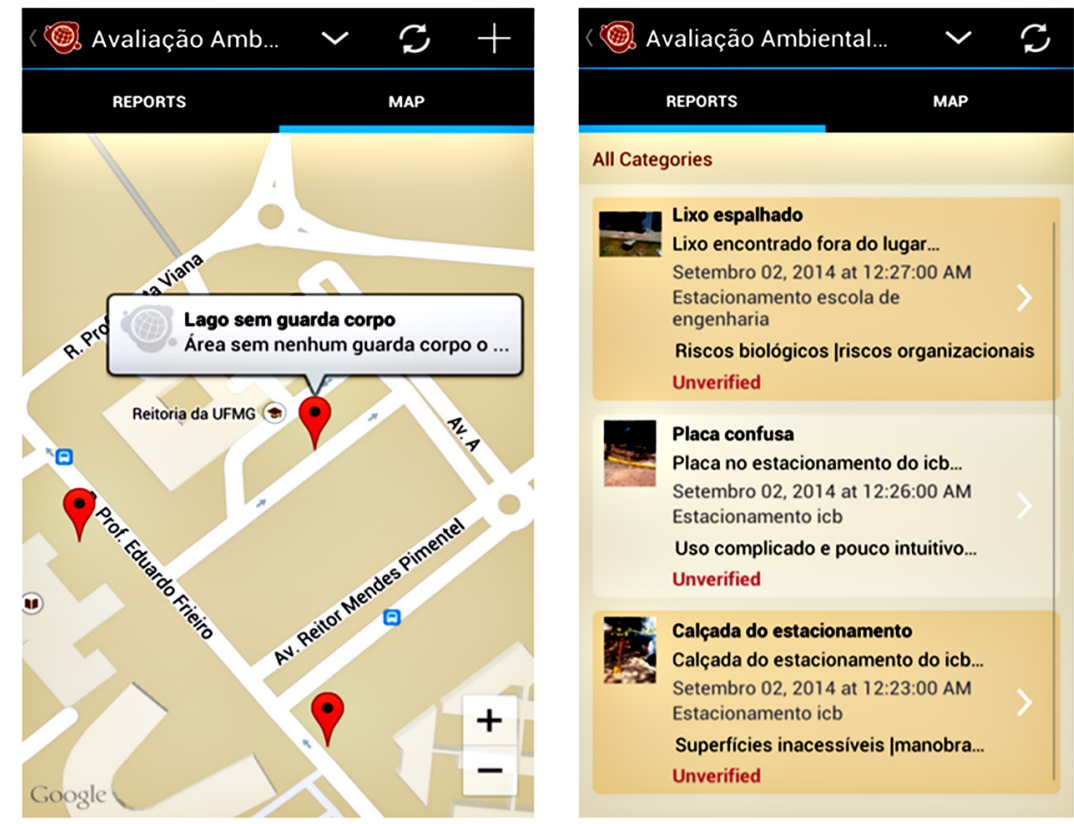

Fonte: Arquivo da Disciplina, 2015 a 2020. Imagens montadas para a disciplina.

Em outro momento da disciplina, uma das atividades consistiu em discutir e contrastar, in loco, as características detectadas na cidade real com as de espaços considerados consoantes com a proposição de uma cidade ideal. Cada grupo apresentaria, em slide e trabalho escrito, sua proposta de cidade ideal (Figuras 5 e 6), justificando a seleção dos requisitos principais, munidos por, pelo menos, cinco referências bibliográficas.

Outro grupo elegeu as disposições inadequadas de resíduos, realçando os riscos e vulnerabilidades presentes nos trajetos percorridos, conforme pode ser visto na Figura 6.
Em 2017, discentes e docentes participaram de uma audiência pública no Centro de Referência da Juventude de $\mathrm{BH}^{7}$ primeiro aparelho público direcionado especificamente para o segmento jovem - público de 15 a 29 anos - em Minas Gerais. O centro dedica-se a promoção de atividades de cultura, lazer, esporte e educação; formação profissional; produção e divulgação de informações de interesse dos jovens; ampliação da formação, do conhecimento, das oportunidades e das habilidades que auxiliem na inserção social dos jovens, articulando-se com entidades e instituições ligadas ao universo da juventude, bem 
Figura 5 - "A cidade ideal poderia ser uma que fornecesse uma boa qualidade de vida a toda população independentemente de classes sociais, raça ou opção sexual"

(Grupo A)
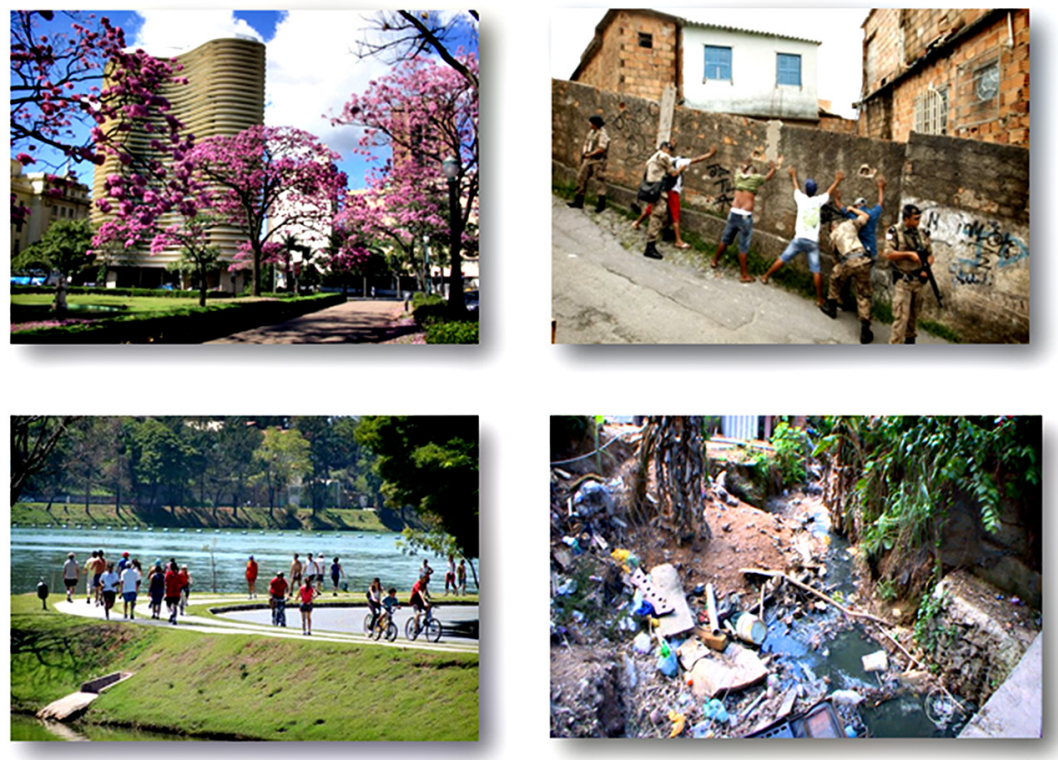

Fonte: Arquivo da Disciplina, 2015 a 2020. Imagens montadas para a disciplina.

Figura 6 - Pontos percorridos, com identificação de aspectos presentes na cidade real em comparação com os aspectos de uma cidade ideal

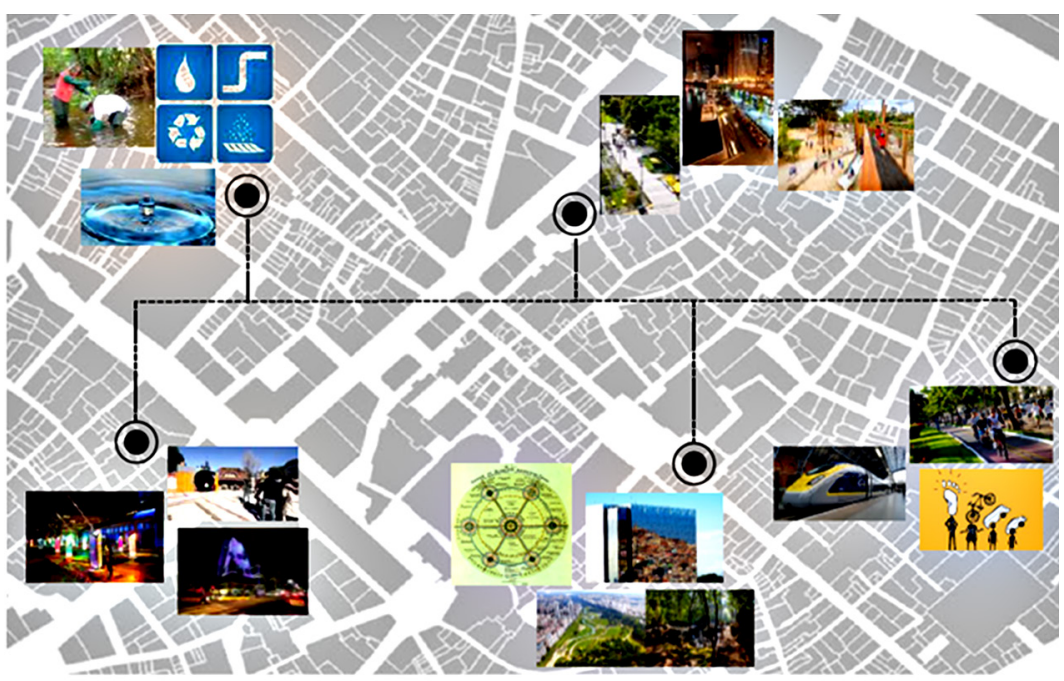

A cidade ideal é uma cidade inclusiva. É uma cidade criada e moldada por um planejamento urbano que visa à redução das disparidades em termos de oferta de bens e serviços, de oportunidades, vulnerabilidades e riscos. A cidade ideal é uma cidade construida por politicas públicas representativas cujo objetivo principal não é a resoluşa de problemas técnicos, estéticos e de infraestrutura. É uma cidade onde as politicas de desenvolvimento săo construidas de maneira participativa, procurando eliminar as barreiras e limitantes sociais e culturais que determinam o acesso aos recursos.

Fonte: Arquivo da Disciplina, 2015 a 2020. Imagens montadas para a disciplina. 
como integração e apoio de iniciativas locais. A audiência contou com representantes do Estado e de comunidade de jovens e acadêmicos que discutiram a questão da violência e o genocídio da juventude negra e pobre (Figura 7).

A participação nesse evento objetivou, além do contato com outras instâncias, examinar, sob a perspectiva dos jovens, o tema da violência, apresentando o papel de "dados espaciais em saúde" e técnicas utilizadas para documentar as condições de vida e de saúde. Compreender os desafios da igualdade na saúde, voltados para os territórios urbanos, principalmente com foco na violência, é uma primeira iniciativa na direção de se estabelecer o diálogo com a educação e a pesquisa, com vistas à promoção de territórios inclusivos, saudáveis e sem violência. Somente avaliando o contexto urbano (ambiente físico natural, construído e ambiente social) e a saúde é que melhor podemos compreender o processo de produção do espaço urbano, centrar na relação de poder desigual e injusto, promotor e delimitador de iniquidades.

Outra prática desenvolvida na disciplina partiu da proposição, em 2018, de incluir, na experimentação dos alunos, o uso do espaço público urbano em condições de mobilidade reduzida, por uma deficiência/limitação física. A pesquisa visava classificar os passeios e identificar, por meio de uma plataforma GIS, os piores trechos em termos de acessibilidade e os melhores, por facilitarem a mobilidade.

A partir da Escola de Arquitetura/ UFMG, considerada uma zona formal urbana, os alunos, em grupos, deveriam percorrer a trajetória proposta, andando pelos passeios, e, ao final, discutir as dificuldades encontradas.

Figura 7 - Escuta pública no Centro de Referência da Juventude de BH em 28/8/2017
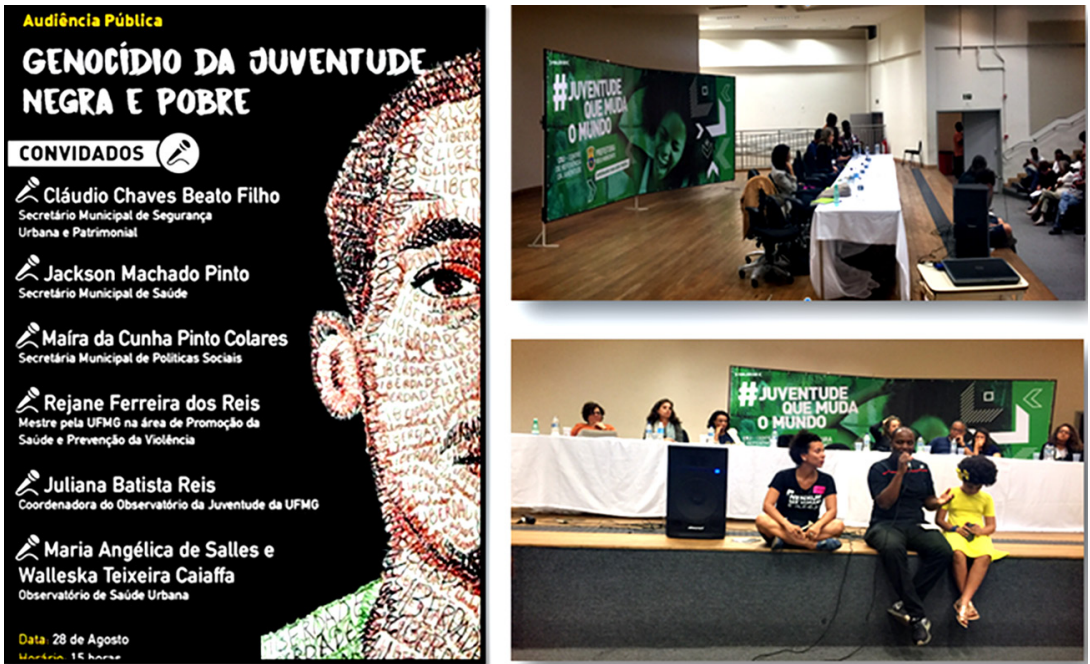

Fonte: Arquivo da Disciplina, 2015 a 2020. Imagens montadas para a disciplina. 
O estudo foi exposto pelos grupos na última aula. A turma foi dividida em quatro grupos com seis integrantes cada, segundo as seguintes deficiências: olhos vendados (representando as pessoas com dificuldades visuais); cadeira de rodas (representando as pessoas com dificuldades de deslocamento e necessidade de se mover ou sozinha com a cadeira, ou com alguém para auxiliar, quando a cadeira não fosse motorizada); protetor auricular (tapa-ouvidos, para limitações de audição) e pernas obstruídas (caminhar com dificuldades, representando os idosos); utilização de pesos (colete ou mochilas com pesos, representando as gestantes e/ou pessoas com obesidade). Cada grupo deveria ter três observadores, sendo dois participantes preenchendo o questionário impresso de forma independente e um participante preenchendo no aplicativo. Um deles seria o relator: um participante que observava as atividades (as dificuldades, sobretudo) de todos os demais, auxiliando quando necessário e garantindo a independência do preenchimento dos questionários (dois impressos e aplicativo). Todos deveriam, individualmente, ao final, trazer por escrito um resumo da experiência vivenciada. Um participante atuaria como acompanhante da pessoa com deficiência (para evitar acidentes) e um participante incorporaria o papel da pessoa com deficiência.

0 resultado foi muito instigante. Muitos alunos jamais haviam atentado para as condições dos passeios e menos ainda quando moIhados (no dia da realização da atividade, havia chovido bastante). Eles também nunca tinham feito a simulação, de se colocarem na posição das pessoas que possuem limitações. Por fim, foram feitas ressalvas quanto ao tratamento que os demais transeuntes têm em relação às pessoas com dificuldades: a maioria sente que aqueles são obstáculos no seu caminho, estão apressados e procuram ignorá-los; poucos oferecem ajuda.

Em 2019, essa atividade foi novamente executada, porém o interesse era avaliar a região hospitalar de Belo Horizonte, em especial a avenida Professor Alfredo Balena e adjacências. $O$ desafio era pensar a reinvenção do espaço urbano em áreas consolidadas, e essa região é considerada uma zona formal urbana. As observações também foram bastante instigantes, em particular por ser uma região que requer cuidados e atenção para com pacientes debilitados, ao mesmo tempo que exige celeridade no socorro das pessoas, em decorrência da localização, naquele espaço, do Pronto Socorro João XXIII, bem ao lado da Faculdade de Medicina. Diversos obstáculos nos passeios e a quantidade de transeuntes foram ressaltados, tendo sido propostas sugestões para a recuperação da região.

Outro estudo, privilegiando as experiências no contexto metropolitano, ocorreu em 2021, com a pandemia da Covid-19. Com o isolamento social, os estudantes dedicaram-se a elaborar uma reflexão analítica e crítica a respeito do conteúdo aprendido ao longo da disciplina, combinado ao conceito de sindemia e ao contexto da Covid-19, em Belo Horizonte (MG). A questão norteadora foi: "Com o evento da Covid-19 há/houve mais controle e regulação sobre o espaço, a sociedade e os corpos? Considere os aspectos econômicos, políticos, ambientais, culturais e sociais". Cada grupo debateria, com maior ênfase, os possíveis mecanismos como e por que a pandemia estaria afetando o eixo sorteado para o grupo: 1) serviços de saúde (atenção primária à saúde); 2) educação; 3) sistema de transporte; 4) políticas públicas e de bases comunitárias 
urbanas, sanitárias e ambientais (organização e mobilização social em áreas vulneráveis); e 5) mudanças no estilo de vida e nos hábitos alimentares. Eles consultaram os boletins informativos do InfoCovid-OSUBH: ${ }^{8}$ que relatam "em tempo" a dinâmica da pandemia em Belo Horizonte, elaborados pelos pesquisadores do Observatório de Saúde Urbana (OSUBH), da Faculdade de Medicina da (UFMG) e revisão bibliográfica. 0 resultado deveria ser exposto nos seguintes formatos: ensaio explicitando o trabalho realizado, um infográfico de linguagem acessível, privilegiando as principais conclusões direcionadas à apresentação para os gestores públicos ou um vídeo de 1,5 minutos preparado para a comunidade em geral.

\section{As manifestações dos discentes e as possibilidades de novas abordagens na intersecção saúde e espaço urbano/metrópoles}

Por trazer uma gama ampla e variada de temas e complexidades, tornou-se rotina pontuar as questões que afligiam docentes e alunos, procedendo-se às revisões críticas e a autocríticas ao longo do desenvolvimento da disciplina. Interessa-nos manter a boa formação e o engajamento do profissional. Para tanto, respeitamos sua autonomia, e, para obtermos o retorno de todo esse empenho, um bom recurso utilizado dentro da prática pedagógica consistiu nas avaliações e autoavaliação dos alunos. Essa ressalva é fundamental, diante da diversidade de procedência dos alunos - designer, arquitetura, biologia, nutrição, geografia, engenharia estatística, enfermagem, educação física, fisioterapia, ciências socioambientais -, o que nos obriga a ter em conta suas singularidades no modo de ver e elaborar o mundo. A seguir, transcrevemos alguns excertos das avaliações dos discentes, para ilustrar o retorno deles quanto às atividades empreendidas na disciplina nos últimos anos.

\begin{abstract}
A abordagem do espaço, cidade, metrópole, urbano e cada dia trouxe contribuições interessantes para pensar a cidade[...]. Em particular, esse tema desenvolvido a partir da perspectiva de Henri Lefebvre, explorado durante a aula, amplifica o conceito de cidade e ajuda a desenvolver uma compreensão crítica e profunda do urbano e seus efeitos sobre a saúde da população [...]. Outro pensamento importante foi sobre o direito à cidade, além das emergências de políticas públicas (por exemplo, habitação), mas também como um lugar de diversão, lazer, aventura, reuniões e isolamento e sobre as possibilidades de estar em um espaço que incentiva a diversidade de ver e estar no mundo. (A. F., doutoranda em Saúde Pública)
\end{abstract}

Pautando as questões alimentares e agricultura:

\begin{abstract}
A palestra sobre agricultura e segurança alimentar urbana quebrou o paradigma de que os alimentos devem ser produzidos somente em áreas rurais. Cada vez mais, a cidade produz o que consome. Essas alternativas devem ser reforçadas como uma fonte de trabalho e renda e uma alternativa para a produção de alimentos mais saudáveis. (F. A., doutoranda em Saúde Pública)
\end{abstract}

A presença de áreas verdes e todos os serviços que delas são emanados e beneficiam os espaços urbanos: 
Outra discussão importante foi sobre a influência de áreas verdes na qualidade de vida urbana, que também traz impacto sobre a dengue (Pessanha et al., 2012), o meu tema de estudo. O crescimento dos centros urbanos leva ao aumento das demandas de infraestrutura, habitação, trabalho, saúde, lazer, educação [...]. Essas áreas podem proporcionar benefícios como conforto térmico, reduzindo a poluição, alterando o abrigo da fauna, equilíbrio climático, organização e composição de espaços para o desenvolvimento de atividades humanas, contribuindo para a saúde e bem-estar da população. (N. C., mestranda em Epidemiologia)

E em termos do conjunto da disciplina:

A participação de diversos professores, conteúdos e práticas proporciona uma experiência extremamente enriquecedora para a disciplina, embora nem todos os problemas se dirijam à aplicabilidade direta ao meu objeto de pesquisa. Acredito que, para o próximo curso, poderiam ser temas mais explorados, relacionados aos estudos de GIS e análises. (T. B., doutoranda em Enfermagem)

\section{Seguindo em frente}

Uma radiografia precisa e com acuidade pretendemos alcançar, e, nessa verve, ainda temos muitos desafios e possibilidades de novas abordagens na intersecção saúde e espaço urbano/metrópoles, de que são exemplos as questões da pandemia Covid-19. Dentre eles, conhecer mais e melhor seu comportamento, adaptações no âmbito da saúde coletiva e também individual, o que exige estudos sérios, profundos e constantes, bem como a lisura na comunicação de seus resultados e conclusões à sociedade em seus diversos segmentos.

Podemos vislumbrar que, cada vez mais, é fundamental para pesquisadores/ras o aproximar-se de todas as comunidades, incluindo aquelas que serão abarcadas pelas políticas públicas, sempre tendo em conta o contexto político e econômico. A mobilização por vezes não foi suficiente para assegurar políticas científicas relevantes e menos talvez em um cenário de desconstrução silenciosa. Urge, então, a criação, o aperfeiçoamento e a consolidação de redes de trabalho em distintas intersecções inter/transdisciplinares e escalas, a fim de refletir e encorajar práticas inovadoras de aprendizagem e práticas profissionais. Os fóruns de debates e de difusão do conhecimento científico precisam resistir à ofensiva de negação da ciência e fazer frente ao desmonte do sistema nacional de educação e universidades públicas.

Partimos da saúde pensando que, ao construirmos uma história coletiva de solidariedades numa comunhão de destinos, é preciso estudar e construir de forma ativa o processo de mudanças para fazer/impulsionar transformações sociais e estruturais significativas. Reconhecemos não ser tarefa fácil escrever sobre/para o mundo com/no mundo, mas é preciso identificar e entender como as sociedades se adaptam a novos modos de viver.

"salvemos vidas" (Arroyo, Humanidades Promestre, 2020). 


\section{[I] https://orcid.org/0000-0002-1355-2192}

Universidade Federal de Minas Gerais, Instituto de Geociências, Departamento de Geografia. Belo Horizonte, MG/Brasil.

pereiradb@yahoo.com.br

\section{[II] https://orcid.org/0000-0001-5043-4980}

Universidade Federal de Minas Gerais, Faculdade de Medicina, Departamento de Medicina Preventiva e Social. Belo Horizonte, MG/Brasil.

caiaffa.waleska@gmail.com

\section{[III] https://orcid.org/0000-0002-1247-2465}

Universidade Federal de Minas Gerais, Faculdade de Medicina, Departamento de Medicina Preventiva e Social. Belo Horizonte, MG/Brasil.

venezaberenice@gmail.com

\section{Nota de Agradecimento}

Agradecemos a todos que possibilitam essa interlocução, em especial, aos professores: Amélia Augusta de Lima Friche, Heloisa Soares de Moura Costa, Janise Bruno Dias, Larissa Loures Mendes, Renato César Ferreira de Souza e Roseli Gomes de Andrade, bem como os monitores: Bruno de Souza Moreira e Denise Marques Sales.

Waleska Teixeira Caiaffa é bolsista de produtividade do CNPq.

\section{Notas}

(1) Concordamos com Morin (2000) quanto aos sete pontos-chave para a educação: a necessidade de encontrar-se às cegueiras do conhecimento (erros e ilusões); entender o conhecimento pertinente; ensinar a condição humana, dentro de todos os aspectos e ótica (ambientais, cósmica, social, afetiva); ensinar a identidade terrena; enfrentar as incertezas; ensinar a compreensão; e, finalmente, a ética do gênero humano.

(2) Remetemo-nos ao Estado de exceção discutido por Agamben (2004) (em termos de relações de direito e poder). O Estado tem tomado medidas de vigilância e de restrição da mobilidade sob diversos pretextos, aguçando as desigualdades sociais e precarizando mais a vida da maioria, notadamente nesse contexto da pandemia da Covid-19 (desde março de 2020, em Belo Horizonte, o isolamento social foi indicado e sugerido como uma das medidas de contenção da pandemia). 
(3) Segundo a ONU Hábitat, "1,6 mil millones de personas no tienen una vivienda adecuada y el $25 \%$ de la población mundial vive en barrios informales sin infraestructura ni saneamiento básico, sin acceso a servicios públicos, con escasez de agua y electricidad. Viven en espacios pequeños donde se aglomeran familias numerosas. En resumen, habitan en la ciudad sin derecho a la ciudad, ya que, viviendo en espacios desurbanizados, no tienen acceso a las condiciones urbanas presupuestas por el derecho a la ciudad" (Santos, 2020, p. 18).

(4) Ver, por exemplo, Leal et al. (2017), a respeito das iniquidades raciais na atenção pré-natal e ao parto no Brasil.

(5) Disponível em: https://pubmed.ncbi.nlm.nih.gov/?term=urban\%20health\&timeline=expanded. Acesso em: 14 abr 2021.

(6) O Projeto BH-Viva (A Saúde dos Moradores em Zonas e Áreas Especiais de Interesse Social) foi concebido para buscar evidências em Saúde Urbana e mensurar os efeitos de intervenções de requalificação urbana multifacetadas sobre a saúde e o bem-estar de moradores de zonas e áreas especiais de interesse social (Zeis). As Zeis correspondem aos locais de vilas e favelas, definidas segundo a Lei de Parcelamento, Uso e Ocupação do Solo do Município (Pereira et al., 2015 citado em Friche et al., 2015a). As intervenções foram desenvolvidas pela Prefeitura Municipal de Belo Horizonte (PBH) como parte do Plano de Aceleração do Crescimento do Governo Federal, denominado, em Belo Horizonte, PAC-Vila Viva ou Projeto Vila Vivo. Descrito como "experimento natural", o Projeto BH-Viva é uma proposta de pesquisa e de aprendizagem cuja hipótese principal é a de que políticas públicas para além do setor saúde afetam favoravelmente o estado de saúde das populações, tanto dos moradores, diretamente expostos, como da vizinhança e de seu entorno, indiretamente expostos. Propõe investigar o impacto do investimento em habitação, requalificação e renovação de áreas vulneráveis sobre a saúde e o bem-estar dos indivíduos, das famílias e das comunidades (Friche et al., 2015a).

(7) Maiores informações estão disponíveis em: http://portalbelohorizonte.com.br/o-que-fazer/artee-cultura/centros-culturais/centro-de-referencia-da-juventude-crj-bh. Acesso em: 12 set 2020.

(8) Disponível em: https://www.medicina.ufmg.br/coronavirus/informacao/infocovid/. Acesso em: 12 set 2020 .

\section{Referências}

ABEP (2017). Brasil ainda mais urbano. Disponível em: http://www.abep.org/blog/pesquisasabep/ brasil-ainda-mais-urbano/. Acesso em: 9 dez 2019.

AGAMBEN, G. (2004). Estado de exceção (Estado de sítio). São Paulo, Boitempo.

ALHO, C. J. R. (2012). Importância da biodiversidade para a saúde humana: uma perspectiva ecológica. Estudos Avançados, v. 26, n. 74, pp. 151-165.

ANDRADE, L. A. E. de (2008). Espaço, política e periferia: as políticas sociais na reprodução das relações sociais de produção. Terra Livre, v. 31, pp. 33-48. 
BRASIL (2016). Ementa Constitucional n. 95 (EC95). Disponível em: http://www.planalto.gov.br/ ccivil_03/constituicao/emendas/emc/emc95.htm. Acesso em: 10 set 2020.

BUSS, P. M. et al. (2014). Saúde na Agenda de Desenvolvimento pós-2015 das Nações Unidas. Cadernos de Saúde Pública. Rio de Janeiro, v. 30, n. 12, pp. 2555-2570.

CAIAFFA, W. T.; FRICHE, A. A. de L. (2012). Urbanização, globalização e segurança viária: um diálogo possível em busca da equidade? Ciência e Saúde Coletiva, v. 17, pp. 2238-2241.

CAIAFFA, W. T. et al. (2008). Saúde urbana: "a cidade é uma estranha senhora, que hoje sorri e amanhã te devora". Ciência \& Saúde Coletiva. Rio de Janeiro, v. 13, n. 6, pp. 1785-1796.

(2010). "Urban Health and Governance Model in Belo Horizonte, Brazil". In: VLAHOV, D.; BOUFFORD, J. I.; PEARSON, C.; NORRIS, L. (orgs.). Urban health: a global perspective. Nova York, The New York Academy of Medicine.

CORDEIRO, E. S. (2020). Como as desigualdades sociais fazem mal à saúde? Curso A Medicina e as relações sociais. Disponível em: https://www.youtube.com/watch?v=wPJ-Uj8YK4A. Acesso em: 12 set 2020.

COSTA, A. M. et al. (2020). Na pandemia da Covid-19, o Brasil enxerga o SUS. Saúde debate. Rio de Janeiro, v. 44, n. 125, pp. 289-296.

COSTA, H. S. M.; COSTA, G. M.; MONTE-MÓR, R. L. M. (2018). Une expérience au Brésil de planification et de projet métropolitain et local: possibilités de convergence et contrôle social. In: COLLOQUE DES 20ÈMES RENCONTRES INTERNATIONALES EN URBANISME DE L'APERAU. Que reste-t-il du projet? Actes. Lille, Aperau, Université de Lille, pp. 19-23.

DAYRELL, M.; CAIAFFA, W. T. (2012). Homicídios e consumo de drogas: breve revisão contextualizada em uma zona urbana metropolitana. Revista Médica de Minas Gerais, v. 22, pp. 321-327.

DE CERTEAU, M.; GIARD, L.; MAYOL, P. (1998). A invenção do cotidiano: 2. Morar e Cozinhar. Petrópolis/ Rio de Janeiro, Vozes.

DIAS, M. A. de S. et al. (2019). Homicídios em Belo Horizonte, MG: um retrato das iniquidades nas cidades. Saúde e Sociedade (on-line), v. 28, pp. 267-282.

FREIRE, P. (1982). Educação e mudança. Rio de Janeiro, Paz e Terra.

(1987). Pedagogia do oprimido. Rio de Janeiro, Paz e Terra.

FRICHE, A. A. de L. et al. (2015a). Intervenções de requalificação urbana e o impacto na saúde: protocolo de estudo "quasi-experimental" com métodos mistos - Projeto BH-Viva. Cadernos de Saúde Pública, v. 31, supl. 1. Rio de Janeiro, 1-S14.

(orgs.) (2015b). Saúde urbana em Belo Horizonte. 1. ed. Belo Horizonte, UFMG.

HELLER, A. (1992). O cotidiano e a história. São Paulo, Paz e Terra.

HUMANIDADES PROMESTRE (2020). Humanidades em Debate - Direitos Humanos, Espiritualidade e Educação, com profs. Conceição Clarete (Promestre/UFMG) e Miguel Arroyo (FaE/UFMG) transmitido ao vivo em 31 de julho de 2020. Disponível em: https://www.youtube.com/ watch?v=rEG_C-Ipes\&t=4648s. Acesso em: 11 set 2020.

IBGE (2017). Dados demográficos para o Brasil. Disponível em: https://www.ibge.gov.br/. Acesso em: 10 set 2020. 
LEAL, M. do C. et al. (2017). A cor da dor: iniquidades raciais na atenção pré-natal e ao parto no Brasil. Cadernos de Saúde Pública, v. 33, supl. 1, pp. 1-17.

LEFEBVRE, H. ([1968] 1991). A vida cotidiana no mundo moderno. São Paulo, Ática. (1969). O direito à cidade. São Paulo, Documentos. ([1972] 2010). Espaço e política. Belo Horizonte, Ed. UFMG. (1976). Reflection on the Politics of Space. Antipode, n. 8, pp. 30-37. (2000). La production de l'espace. Paris, Anthropos. (2008). A revolução urbana. Belo Horizonte, Ed. UFMG.

MORIN, E. (2000). Os sete saberes necessários à educação do futuro. São Paulo, Cortez.

PEREIRA, C. V. L.; AFONSO, A. S.; MAGALHÃES, M. C. F. (2015). Programa Vila Viva: intervenção em assentamentos precários. Disponível em: http://portalpbh.pbh.gov.br/pbh/ecp/contents.do?ev ento=conteudo\&idConteudo=22546\& chPlc=22546\&\&pldPIc=\&app=salanoticias. Acesso em: 26 fev 2019.

PESSANHA, J. E. M. et al. (2012). Diffusion Pattern and Hotspot Detection of Dengue in Belo Horizonte, Minas Gerais, Brazil. Journal of Tropical Medicine, v. 2012, pp. 1-11.

RALÓN, G. et al. (2012). De los estudios locales a una perspectiva regional: análisis integrado de datos secundarios en un proyecto colaborativo sobre vulnerabilidades asociadas al uso de drogas en Argentina, Brasil y Uruguay (1998-2004). Salud colectiva, v. 8, pp. 229-246.

RÖHR, F. (2011). Espiritualidade e formação humana. Poiésis, Tubarão, número especial, Biopolítica, Educação e Filosofia, pp. 53-68.

SANTOS, B. de S. (2020). A cruel pedagogia do vírus. Coimbra, Almedina.

SHAREAMERICA (2015). Ushahidi: usando mídias sociais para salvar vidas. Disponível em: https:// share.america.gov/pt-br/ushahidi-usando-midias-sociais-para-salvar-vidas/. Acesso em: 12 jan 2020.

SOUZA, M. J. L. de. (2000). “O território: sobre espaço e poder, autonomia e desenvolvimento". In: CASTRO, I. E. de et al. (orgs). Geografia: conceitos e temas. Rio de Janeiro, Bertrand Brasil.

SOUZA, R. C. F. de et al. (2016). Viver próximo à saúde em Belo Horizonte. Cadernos Metrópole, v. 18, pp. 326-344.

Texto recebido em 30/set/2020

Texto aprovado em 12/jan/2021 